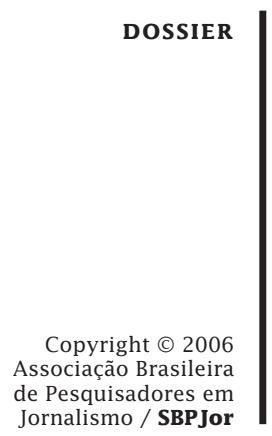

MEDIA WATCHERS

\section{A profile of press criticism in Latin America}

ROGÉRIO CHRISTOFOLETTI

Universidade do Vale do Itajaí, Brazil

SUSANA HERRERA DAMAS

Universidad de Piura, Peru

\begin{abstract}
Media watchers are recent actors on the Latin American media scene, including the Brazilian one. However, there are examples of monitoring activity spread around the entire continent. Over and above contributing to the improvement of mass media, the observatories help to diffuse a culture of critical consumption of information. That contributes to the development of democracy by promoting values such as transparency, freedom and citizenship. This article reflects, initially, on the conditions of the Brazilian media market. Following that, it evaluates the obstacles to the dissemination of a media criticism culture. At a third moment, the focus is amplified and a profile of Latin American media watchers is provided, emphasizing characteristics in common and aspects that distinguish them.
\end{abstract}

KEY-WORDS

Journalistic sources, journalism, technology, cognitive sciences, biological memory.

The restoration of democratic political systems, the reconstruction of solid institutions and the spreading of a culture attentive to citizens' rights are processes that have been redrawing the map of Latin America. These are subtle gestures, but very relevant regarding the construction of a new history for this region that in the last century was one of the major antidemocratic laboratories of the planet.

It is true that Latin America is far from the political stability established for decades in North American and European countries, for example. However, the present reality among Latin Americans is already much different from the one observed in the 1960s and 1980s, marked by disturbances in their political systems. In that period, most of the Latin countries underwent military interventions and dictatorial regimes. 
The alteration of geopolitical coordinates favored things for Latin America. The Cold War lost its strength; Asian powers became prominent; the Middle East projected itself far beyond petroleum cartels; the United States changed the focus of its foreign policy. Most of the Latin American dictators were history and the return of democracy brought back more values than the mere choice of public representation and power alternation. Principles such as civil freedom, citizenship serving as a pillar of support for democratic societies and accountability emerged emphatically in public debates.

In recent decades, Latin American citizens became more mature, and so did their institutions. Mass media followed this development and played a crucial role in the diffusion of values in a democratic culture. Freedom, citizenship and transparency took over newspaper columns, TV and radio stations, the Internet and magazines. And the intervention for the reinforcement of transparency in Latin American public life may have been the major contribution of the media to Latin American progress (HERRERA \& CHRISTOFOLETTI, 2006).

In many parts of the region, the media incorporated the role of a Fourth Branch, supervising the Executive, Judicial and Legislative Branches. But for complete effectiveness of the transparency principle, not even the media can escape from supervision, vigilance and attendance. In this context, media observatories become important social tools for the exercise of criticism, institutional monitoring and elevation of the public to an active position in the process of communication.

Media watchers take on an important role in what can be called a "media literacy training program". That is to say, the media do not exercise just criticism, but also analyze themes that could call the public's attention to a less naïve and passive reading of the media, encouraging debates, comparisons and deeper observations. In this way, media watchers help to promote the emergence of consumers who are more critical and proactive in the consumption of information in this wide market of facts, opinions and versions.

But it is not always easy to introduce systems for evaluation in the media. In Brazil, for instance, the obstacles are inherent in the system of communication, in our present legislation and even in society's mentality. 


\section{Brazilian media market and the possibility of criticism}

In Brazil, media criticism is limited to a few areas, generally of an alternative nature, and has no relevant impact on most of the public. It is a sort of confinement, which relegates reflection on the practices and nature of mass media to second place. In other countries, such as the United States and France, the media cover the media, and the discussion about procedures of professionals and corporations is open, reaching several layers of society and influencing, in a conclusive way, the social structure.

Non-governmental organizations such as FAIR (Fairness and Accuracy in Reporting) and Media Watch can already be considered American institutions of free thinking and freedom of expression. In France, Le Monde Diplomatique is a publication which deals with themes that involve the media universe.

In Brazil there is no tradition, courage or disposition for undertaking major initiatives that function in the sense of providing a critical reading of the media. Experiences that overcome these obstacles subsist in some isolated examples of a private nature, in the third sector and in the academic world.

In the first case, the institution of the ombudsman by the newspaper Folha de São Paulo has stood out since 1989, and has been surpassing the expectations of the market. After more than fifteen years and eight journalists occupying this position, Folha's ombudsman has been well absorbed by the market and has even motivated smaller newspaper companies. Besides, the consolidation of this instance of journalistic product evaluation assured a small basis for criticism and self-criticism in journalistic corporations.

Among non-governmental institutions, there are efforts that resulted in the Observatório da Imprensa (Press Observatory) - which was born on the Internet, made its way through television and has recently attempted entry into radio - and in the Children's Rights News Agency (ANDI), that monitors mass media, performs research, suggests sources and journalistic guidelines for the coverage of problems that involve children and adolescents in Brazil.

However, it is in the academic environment that media criticism seems to find more possibilities for implementation as a reflexive exercise and tool that suggests new procedures. That is understandable because the university is an environment that is safe (with a certain immunity to market pressures), productive (because it is a place where solutions to 
problems and explanations for phenomena and situations are expected), reflexive (as an established knowledge-generating pole) and plural (offering varieties of public and theoretical perspectives).

Since November 2005, a network of researchers that systematically monitor Brazilian media has been in the process of formation. Some of them have worked with it for a while, others for not so long, but it is a fact that the idea of media watchers has already been known for ten years. In 1996, with the emergence of the Press Observatory, there was a clear intention to implement in schools of communication similar projects for media watching and media criticism. There were many attempts to create this network, which only happened recently, at a time of the full consolidation of the Press Observatory, the maturity of research in Brazilian journalism and the joint efforts observed in the country.

Consolidated by the Press Observatory, the National Network of Press Observatories (RENOI) includes today 31 researcher-teachers and 220 students. The network is active in ten states in all the regions of Brazil: São Paulo, Paraná, Santa Catarina, Espírito Santo, Sergipe, Paraíba, Minas Gerais, Rio Grande do Sul, Pará and the Federal District. It includes fourteen higher education institutions, four of which are public and ten private, plus the PROJOR, a non governmental organization that supports the Press Observatory and also ANDI. There are sixteen units in the network that already have media monitoring projects or that are developing their initiatives.

RENOI concentrates its work on ten observatories in the network: SOS Press (http://www.unb.br/fac/sos), Analysis of the Media (http://www. usc.br/analisedemidia), Press Channel (http://www.canaldaimprensa. com.br), Media Monitor (http://www.univali.br/monitor), Media \& Politics (http://www.midiaepolitica.unb.br), Unama Agency (http://www.agencia. unama.br), Studies of Brazilian Journalism (http://jornalismo-capixaba. blogspot.com), ANDI (http://www.andi.org.br), RENOI Vale do Paraíba (http://www.csonlineunitau.com.br/renoi) and Press Observatory (http:// www.observatoriodaimprensa.com.br). There are also four projects in process: Research Group of Daily Newspapers and Journalism, Journalism Studies Lab, MonitorES Unilinhares and RENOI - Uberlândia.

Most of the time projects count on websites to disseminate their research work and perform the job of monitoring mass media. In its first year of implementation, RENOI has been very active from a productive point of view and also very consolidated in its relations. Its members have frequently exchanged information with the help of e-groups, updating experiences and news. In addition, debate groups are articulated 
at academic events in order to strengthen contacts and disseminate initiatives on the network.

However, if RENOI is an option for media criticism dissemination in Brazil, there are other aspects that raise barriers to a more significant participation of society in this process.

\section{Obstacles to a culture of media criticism}

A culture of media criticism does not spread easily in Brazil because of a number of reasons that are based on the logic of the Brazilian communication system, on the legislation that provides legal support and on the mentality of the producers and consumers of information. There are at least ten impediments to an effective media criticism system in Brazil (CHRISTOFOLETTI, 2004):

- Concentration in the communication field

- Flexibility that permits cross ownership

- Electronic "coronelismo"

- Restrictions in frequency allocations

- Practically eternal concessions

- Archaic, obsolete press law

- Impossibility of revoking professional registration

- Difficulties in communication councils

- Conservative behavior of managers in the field

- Autism of the society

On the national scale, concentration of the media market is found in all regions and is almost always based on the same formats: there are large regional conglomerates of mass media, managed by families that are politically and financially influential. It is presumed that today seven groups control $80 \%$ of everything that is seen and heard in Brazilian media vehicles.

The strong presence of these groups in Brazilians' daily informative and entertainment life takes the form of a total presence. The size of some groups is enormous in the context of national economic market data. In Brazil, there are 41.1 million homes with television sets, a number higher than that with refrigerators. As a rule, there are 1.25 television sets per home, and a Brazilian will spend 3 hours in front of his television set, from Monday to Saturday, according to DataFolha in September 2000, when TV completed 50 years in the country'. In 1999, company figures revealed that the total gross billing on open signal channels was $R \$ 4.4$ billion. 
The focus on media business hinders the entrance of new companies, styles and contents in the market. Worse: it turns news into patterns and pasteurizes entertainment. Powerful people who are in control are against criticism and contestation of their procedures. When it comes to television and radio stations, which depend on public concessions to operate, the case is even worse, since in that sector, commitments made to obtain the permission for exploitation, including social services, are simply left aside.

The system permits cross ownership, which intensifies the control of content. Contrary to other countries, Brazil has a confusing legislation, full of gaps, which permits the practice of cross ownership: the same group controls corporations in the radio, television and Internet fields. This converts news produced in one media vehicle into a reproduction of another vehicle's material, ignoring characteristics of its own environment and local and regional aspects. It also permits opinions, values, symbols and versions of events expressed by powerful corporate groups to be disseminated in a uniform and perennial way along several lines, reinforcing the diffusion of these ideas, increasing their range and penetration.

The detailing of the groups' ramifications shown above is an example of the capillarity of the market, and reveals the existence of a permissive State, compliant with a situation based on little competition. Cross ownership contributes to the process of concentration, favoring the expansion of these businesses and giving the impression of financial power and informative credibility to the consumer. It is a strategy for occupation of multiple spaces in the minds of the citizens, an attempt to fill up completely the available time of consumers of information and entertainment.

Allied to concentration and cross ownership is what has been called hereabouts "cyber coronelismo", a modality of domination, domestication and political oppression. The expression is typically Brazilian and is based on the existence of powerful regional chiefs, nicknamed "coroneis" (colonels) in the northeastern region of the country.

If in the middle of the 20th century these "coroneis" influenced masses of rural workers to vote for candidates who served their interests, nowadays this power is exercised by the domination of radio and television broadcasting stations that help maintain the status quo.

In 2001, a survey by Folha de São Paulo revealed that $24 \%$ of Brazilian radio corporations belonged to politicians. This meant that of every four stations, one was under the wings of someone holding political office. A 
research work performed last year ${ }^{2}$ indicates that one of every ten federal deputies is the direct owner of a broadcasting station, which means to say that these corporations are registered in their names. At least 50 deputies and another 25 senators - directly or not - control a radio or television station, a fact that violates the Federal Constitution.

The fact is that this distribution indicates that broadcasting concessions were historically used in political bargaining between parties that supported government administrations in the Legislative Branch. And in some regions of the country, political domination of mass media is fundamental for maintaining the hegemony and oligarchy of specific groups. This clearly happens in the Northern and Northeastern regions.

Directly connected with the matter of concessions, there are two other aspects that obstruct the dissemination of a culture of media criticism in Brazil: restriction in frequency allocations and practically eternal concession availability. Concentration of media and almost no possibility for the entrance of new groups in the exploitation of communication businesses result from another restrictive factor in the Brazilian national pattern: the inexistence of regulations for opening community radio stations. Weaknesses in legislation, inefficient inspection patterns in terms of technique and context, and lobbies for big and medium-sized stations turn the radio dial into a place reserved almost exclusively for commercial radio stations.

On the other hand, although radio station concessions are of a public character, with established periods for exploitation and performance of social services by their beneficiaries, their revocation is a rare event in Brazil, almost non existent. The general rule applied is the automatic renovation of these concessions for the corporations, creating eternal domains in some parts of audiovisual space. The legislation contributes to this state of things, as well as government inefficiency when it comes to inspecting and controlling concession holders. There is no demanding of quality production and context on the part of the State. And society does not speak for itself either.

From an institutional point of view, the legal system itself can do nothing more. Two obstacles not only clutter up the courts, but also restrict professionals in communication and other areas of society. One is personified by an archaic, obsolete law and the other by the impossibility to revoke the registration of professionals that commit crimes involving the press or serious ethical faults. The so-called Press Law dates from 1967 and has not accompanied technological evolution nor society's development. The truth is that many lawyers put more faith in the 
Criminal Code - when it is a question of crimes of opinion - than in this specific law.

Being resistant to a wider debate of the role of mass media and quality in media vehicles, professionals of the area - even if they wanted to regulate their own labor market - encounter limitations. Due to this porosity, all sorts of individuals arrive at newsrooms, news studios and behind the scenes, many times unprepared to practice the profession and with no ethical basis.

Unlike doctors, engineers and lawyers, Brazilian journalists cannot revoke the registration of unqualified professionals, for the purpose of requiring a minimum level of qualification for those who are working in the market. The government Labor Department grants registrations, and also suspends them, which is rare. Journalists have tried to change this situation by transferring this prerogative to a legitimate professional entity, such as the Brazilian Bar Association for the lawyers. For this purpose, a bill was presented in 2004 to the Brazilian Congress for the creation of a Federal Journalism Council, a controversial proposal that ended up being rejected. The National Federation of Journalists (FENAJ) - the main articulator of the bill - promises to take up the case again in the near future.

Three other barriers to the dissemination of an effective media criticism in Brazil are: the non-functional reality of mass media, the conservative way of thinking of media business managers and a sort of autism of society towards its relation with communication.

Some of these aspects that prevent the dissemination of a culture of media criticism in Brazil are also observed in other Latin American countries. At least superficially, the realities are quite similar, which allows us to draw a basic profile of media watchers in the region.

\section{Methodological Aspects}

It is not easy to characterize a reality that is in constant motion. This is because, among other things, media observatories are experiments that just emerge and "do their own thing", according to Rey (2003). These undertakings are recent and few, compared to American projects such as FAIR, which has been operating for twenty years. However, because they are introduced in realities that seek economic, social and political stability and because they monitor a not-so-autonomous media system, Latin media watchers have a more strategic function in the consolidation of democracy than American ones. For these and for other reasons, efforts 
should be made in an attempt to identify and classify experiences related to media monitoring on the subcontinent.

In order to trace a profile ${ }^{3}$ of the nature, structure and functioning of Latin American media watchers, we have followed some methodological guidelines.

a) As a representative example, we have taken into consideration ten experiences observed in six different countries: Press Observatory, Children's Rights News Agency (ANDI), Media Monitoring and Brazilian Media Watchers, in Brazil; Veeduría Ciudadana de Comunicación Social and Observatorio de Medios, in Peru; Observatorio Fucatel, in Chile, Observatorio Global de Medios, in Venezuela; Observatorio de Medios de la Universidad de La Sabana, in Colombia; and Observatorio de Medios UTPBA, in Argentina.

b) We have followed the work of these observatories through information available on their websites.

c) We have also interviewed by phone some representatives of these observatories. These interviews were based on a semi-structured questionnaire and were carried out from May to September 2005.

d) Finally, the information relating to these observatories was compared and traces of difference and resemblance were identified.

\section{Common aspects of media watchers}

There are at least ten aspects that are common to the media watcher projects analyzed here. The first of them is the recognition of the importance of communication and its media for the consolidation of modern democracies. According to Wolton (1995:145), democracy is not possible without communication and, on the other hand, communication cannot be separated from a model of mass democracy. Both realities - democracy and communication - are thus inseparable. Rey (2002) recalls that the most solid values of democracy are deeply related to communication

Among the reasons that justify this confluence is the conviction that maybe dialogue is not the solution to all problems, but it is a part of the solution. It is in this context that media watchers become a possible alternative for resolving conflicts. If democracy is the system with the broadest social and individual freedoms and allows the participation of citizens, mass media are the main tools for assuring this system's future and validity. According to Alfaro (2005: 17), mass media are now "the real politicians in the country, absorbing the social representation that politics 
left aside'. Besides, public action of the media is so indispensable for the formation of modern society that it has become one of the determining factors of contemporary society (BENITO, 1978).

In a general way, all media watchers act having as their backdrop the social relevance of media for society, and furthermore they take into consideration the extensive power that these media can exercise in structural changes.

Despite the transcendence that media watchers grant to communication in general and to mass media in particular, there is still a general perception that these media are not doing things the way they should and that their professionals are in a really delicate situation. There is dissatisfaction with the present situation of the media, and this feeling is another common aspect among media watchers analyzed. These examples of observation justify their relevance precisely by questioning the role, orientation, procedures and practices of mass media, according to Rey (2003). In a general way, criticism of the media exposes the questionable way of performing journalism, based on triviality, exaggeration, superficiality, tyranny of events, dramatization and focus on making spectacles of reality or even by seeking a negative focus (bad news, good news). There is also criticism of the lack of strictness in investigation, imprecision, defamation, use of the media for strictly commercial and political purposes, invasion of privacy, the search for information by illegal means and the subordination of the public interest to other interests. The list of media watchers' criticisms of the present situation of the media extends to aspects such as concentration of communication and submission of the journalism industry to certain ideological interests.

If media watchers are critical of the performance of the media and of journalists, one consequence is the quest for another way of understanding and performing the practice of journalism, a third aspect in common among Latin American experiences. Believing in another kind of journalism, media watchers support a more pluralist, severe, precise, balanced and fair modus operandi. Besides that, journalists and the media should listen to citizens' interests, discussions, tastes and preferences; they should be more committed to impartiality, denunciation and the search for truth; they should allow a more democratic media practice. An example of this is a group of Latin American communication organizations which met in Quito, Ecuador, at the Social Forum of America, in July 2004. Based on the interpretation of communication as a basic human right that extends to all individuals, these organizations reinforced the comprehension that communication and journalism must favor social 
inclusion, in order to express differences and seek a common well-being. Communication and information technologies can serve as useful tools for full human development, more democratic and sustainable. In their search for another form of journalistic practice, media watchers also advocate the engaging of consumers, which is another element in this informative equation. In other words, media watchers recognize that a change in certain aspects of the profession does not depend only on their efforts, but also on the level of the users' commitment to this task. That said, another mission of observatories is to educate people to critically consume information and demand higher quality journalism. It is a matter of expecting a more active behavior from the public, as opposed to a characteristic passivity. This understanding leads to another aspect in common among Latin media watchers: the advocacy of another, more participative kind of consumer public.

The constancy of media watchers practices is another aspect that is common to Latin American media watching projects. In a general way, there is a constant, regular and systematic practice of monitoring. It is not a matter of an isolated, circumstantial and temporary case. That being said, media watchers emerge as a profession that sustains itself and grows in time, with continual progress in the analyses and in the monitoring of the media that are performed. Taking into consideration historical series, comparing situations and making comments, observers achieve a deep level of understanding and their criticisms take on a higher degree of legitimacy. It is true that the intensity observed throughout the monitoring varies from case to case. There are observatories that follow, on a daily basis, what mass media publish, while others concentrate on certain occasions such as elections, for example. But regardless of the variations in intensity and frequency, the monitoring is customary and orderly.

The constancy of these efforts is due to a desire for revision and reform. This means that Latin American media watchers act at the level of offering contributions to the development of the media and its professionals, as well as its processes. The criticism practiced by the examples of media watchers is not an end in itself, but a way to reach higher levels of techniques in the media. This intention of reform is what distinguishes Latin American observatories when compared to similar ones in other regions. In Spain, for example, media watchers perform analyses of how the media approaches certain contexts (health, immigration, etc). Among Europeans, the closest reference is the Observatoire Français des Médias, 
connected to Media Watch Global and created after the 2003 World Social Forum, not to mention others from Latin America.

It is understood that Latin media watchers are not unique in their desire for reform, but that aspect is the essence of examples analyzed here. This is observed in a more radical and expressive way from the parallels, because another characteristic reinforces this situation: local media watchers have a suggestive character and a more prescriptive than descriptive purpose. This stimulates them to formulate new practices, styles and possible contexts in a critical but non-destructive way. An example is the Veeduría Ciudadana, in Peru, which concludes its investigations only with propositions, guidelines and suggestions for media development. In 2002, the observatory evaluated children's programming on Peruvian television and from this analysis and public consultation, developed an extensive guideline for changes directed to television owners and producers, advertisers, and the related fields of the educational system, the State and the family. Three years later, Veeduría performed a similar survey, but focused on gender equality in television programming ${ }^{4}$.

The performance of Veeduría compared to other cases - such as the Press Observatory or even ANDI - denotes another aspect that can be credited to Latin media watchers: the diversity and creativity in their forms of operation. In a general way, the initiatives evaluated share a strong commitment to action. Connections between observation and concrete action are also identified in Broullón, Hernández, López y Pereira (2005), who recognize in this characteristic something of the profile that we hope to trace. But it cannot be said that there are two observatories working in the same way. In this connection, what can be seen is that the need for a wider variety of activities challenges the creativity of those who are involved in media watching.

A ninth characteristic in common among these cases is the conviction of the importance of disseminating publicly their activity. Media watchers need to announce the result of their surveys to a wider public, trying to exercise a critical pedagogy with regard to information consumption. Making these activities public turns them into one of the first works that, in some cases, open the door for other ones. Again, it is not a matter of disseminating just for the sake of disseminating, but rather a task of inclusion and dissemination of themes that concern mass media and their development.

Concerning the dissemination of activities and results of analyses, Latin media watchers have a special preference for the use of new 
technology. In any case, all media watchers expressed this preference, mainly for the Internet. Low budget, great flexibility, accessibility, speed, penetration in society and simplicity of use are advantages. The Internet is a technological support and is the place where media watchers are born, leading them along a path that enables the development of activities and dissemination of results more widely and in at an economical way. The tools most used are websites, blogs and newsletters.

In some cases, the use of the Internet is important not only for the dissemination of media watchers' work, but also for the internal operations of their professionals. Veeduría Ciudadana and Latin American ANDI use the web to articulate their activities and coordinate actions in other countries.

These are aspects in common among media watchers. However, this reality is not uniform, and for this profile an enumeration of what helps to distinguish each media watching experience is needed.

\section{Differences between media watchers}

The figure of media watching assumes, in Latin America, a wide variety of shapes and is seen as a versatile mechanism, with a configuration in accordance with the creativity of those who perform it. Nevertheless, it is important to recall that this is a recent development, whose outlines are still being defined. In any case, the main criteria for differentiation of observatory activity are based on the diversity of their origins and methods of functioning, on the variety of their make-up, on the aspects analyzed and methodological tools and on the disparity in ideological orientation and in the systematization of the activities.

Even though observatories arise as a result of the perception that the mass media are in a critical situation, the initiative for a project like this can arise in three distinct spheres, according to Rey (2003): the academic world, the market and organized society. Media watchers linked to universities and communication courses, based on a mainly academic perspective, recall what should be the role of the media in contemporary societies and reinforce the need for journalists' conduct to be guided by ethical and quality parameters. Projects that fit into this type of origin are Media Monitor, in Brazil, and the Observatorio de Medios da Universidad de La Sabana, in Colombia.

The second case involves observatories initiated by press professionals themselves, devoted to critically analyzing market practices and suggesting corrections in the procedures adopted by their 
peers. Examples of this type are the Observatório da Imprensa (Press Observatory), in Brazil, and the Observatorio de Medios de la Unión de los Trabajadores de Prensa de Buenos Aires (UTPBA), in Argentina.

A third group is made up of media watchers that arise from organized initiatives of society. Professional journalists can participate in them, but most participants are volunteers and are not involved in the professional practice of communication. Veeduría Ciudadana, in Peru, is the most typical case.

Directly connected to diversity in their origin, Latin American media watchers also diverge on the composition of their groups. These formations also follow three models: when they are formed only by teachers, students and academic researchers; when they are made up of only journalism professionals; or when they unite these components plus other socially organized elements, such as associations, nongovernmental organizations (NCOs), corporations and councils.

A third distinctive aspect of Latin American media watchers is the ideological orientation that inspires their actions. Rey (2003) calls it "political orientation". What this research verified was that media watchers are mechanisms analogous to other media criticism experiences, such as associations of consumers and media users. In the United States, for example, the classic reference is to Fairness and Accuracy In Reporting (FAIR) and Accuracy In Media (AIM) as examples of observation from opposite perspectives: liberal and conservative, respectively.

Leaving aside the distances, Latin American media watchers differ also in their ideological orientation, and this can be expressed in a more or less clear way, always taking into consideration the monitoring activity. Among the cases evaluated in this research, it was observed that most Latin American observatories are more liberal than conservative. These positions within a political spectrum were confirmed by the media watchers themselves, when asked about the ideological orientation of their groups.

Subcontinent observatories are also different when it comes to their operational structures. The possibilities range from the most informal and flexible observatories to those that have their existence formalized in documents, such as founding minutes, bylaws, etc. An example of the first kind can be found in Veeduría Ciudadana de la Comunicación Social, which has no statutes in order to make its work faster and more flexible. At the opposite end, we find the experience of Observatorio Global de Medios in Venezuela, a much more formal organization that has documents devoted to defining and consolidating the project, besides presenting it publicly. 
On the other hand, the ANDI media watcher is a very different type of experience. ANDI is in reality the Children's Rights News Agency that monitors mass media as one of its strategies for mobilizing and making people sensitive to the subject. The results of its analyses contribute to a better quality in the treatment of themes related to children and adolescents. Even though its influence was confined, initially, to the Brazilian capital, ANDI has slowly expanded and reached other regions. This was the motivation that justified the birth of the ANDI Brazil Network, in March 2000, with the clear objective of articulating several communication organizations in the advancement of Brazilian children's rights.. Today, this network includes eleven associations, giving rise to the ANDI Latin American Network. Similarly, the idea is for the entities of ten countries that today comprise this group to use the methodology first created by ANDI.

The variety of aspects analyzed by media watchers is another point to be highlighted. Some of the themes that call more attention are the way that subjects related to children's and adolescents' rights are treated, matters of gender, the role of the media in the representation of internal conflicts, the relation between information and elections, human rights, intimacy, third age, among others. Not only did the themes vary, but also the focus given them. This double thematic specialization - content and focus - could be an element in common between Latin American and European media watchers, since thematic specialization is also one of the current trends observed on the old continent. However, even though each observatory centers its attention on specific themes, it can be affirmed that they are all interested in the evaluation of the coverage in terms of an ethical journalism. In the words of Broullón, Hernández, López and Pereira (2005), the evaluation of ethical criteria in the media is a constant aspect that can be noticed in all observatories. Apart from this shared concern, the themes analyzed are very different among the media watchers analyzed.

Methodological tools also vary. In this aspect, it should be clear that the term "methodology" indicates the way in which the media focus on problems and search for answers. The choice of one methodology or another depends on the media watchers' principles, interests and objectives. The results of this investigation indicated that a high number of Latin media watchers give great importance to the use of rigorous methodological tools not only as an indispensable quality that any observatory should have but also as a guarantee that exempts analyses from the subjectivity of their authors ${ }^{5}$. 
Regardless of this perception, what is seen is also a high diversity of techniques used. Most of them practice simple monitoring - based on the tracking of a variable in a group of media without excessive systematization, depth or strictness - and others complement the result of their analyses with other more sophisticated and refined techniques such as Content Analysis, Discourse Analysis or Narrative Analysis. Among the latter, Content Analysis deserves special attention due to its high potential for the study of journalistic messages, even though - as mentioned before - few use it as a methodology of media observation. In this connection, there is a certain contradiction between what is considered theoretically or conceptually - the importance of having refined tools available for analysis - and the fact that, in practice, readings become many times reduced to the use of a single technique that, on the other hand, is less rigorous.

The element that shows the highest variation among the ten observatories analyzed is related to operating methods. The diversity of these systems displays the greatest range of variation and versatility in Latin American cases. But in which concrete aspects do the subcontinent's experiences differ? In many ways. For example, in the number of people who take part in an observatory, in its hierarchical structure, in its funds and its form of financing. All these aspects challenge the creativity of media watchers.

Regarding the forms of financing, for example, there are initiatives that support themselves through private donations, others through members' dues; others survive by subscription, and there are cases that receive public subsidies. Besides these forms, the commercialization of research works, publications or reports, funds from the institution to which the observatory belongs - as in the case of those maintained by schools of communication - and the support of Brazilian or international non-governmental organizations constitute in practice other possible solutions. The survey shows that observatories that count on mixed financing and that have the support of two or more sources of funds are rare.

A last aspect of differentiation between Latin American media watchers relates to the disparity in the systemization of activities. The intensity, the frequency and the media that media watchers accompany vary. Intensity refers, first of all, to the degree of detailing utilized in the analyses. In some cases, it is more moderate and only a slight reference is made to the topics dealt with, to some general methodological aspects, and to the most relevant conclusions. At the other extreme are the observatories that systematize the results of their analyses with a high degree of detailing. 
The frequency of analysis systemization varies in different observatories, from weekly or fortnightly updates to other intervals, such as monthly or quarterly..

Finally, the documents that media watchers use to systematize their activity are also different in each case. They can include reports, annual publications, memorandums, Internet files or even their own publications. In this matter, the Internet - due to the low cost when it comes to creating a website, its great flexibility and potentially high social penetration - is once more the most indicated technology not only for disseminating the results of the observatories' analyses, but also for systematizing their procedures.

In conclusion, the results of this survey reveal the existence of an ample diversity of elements and of numerous manifestations of the same phenomenon, that of media watchers. Despite the several elements shared by them, the everyday activity of these Latin American observatories provides an extensive margin for the creativity, versatility and imagination of their participants.

\section{NOTES}

1 TV Brasileira: 50 anos - mudar para não mudar (Brazilian TV: 50 years - change in order not to change). Folha de São Paulo, September 16, 2000.

2 In violation of the law, 1 out of every 10 deputies has a TV or radio station registration. O Estado de São Paulo, July 2, 2006.

3 Some of the results were already displayed in Herrera (2005) and Erazo (2006).

4 The same observatory was decisive in discussions regarding the new Radio and Television Law, promulgated in 2004, that brought advances to the field. Veeduría even presented an alternative bill.

5 More than $75 \%$ of the interviewees emphasized the use of rigorous tools as an indispensable quality for the existence of media watchers. 


\section{BIBLIOGRAPHY}

ALFARO, R.M. (ed.). Hacia nuevas rutas éticas en nuestros medios. Memoria de la campaña ciudadana sobre la Ley de Radio y Televisión. Lima: Veeduría Ciudadana de la Comunicación Social, 2005.

BENITO, Á. La socialización del poder de informar. Madri: Pirámide, 1978.

BROULLÓN, G., HERNÁNDEZ, T., LÓPEZ, X. y PEREIRA, J. "Los observatorios de comunicación”.In Chasqui, núm. 90, 2005: 38-45.

CHRISTOFOLETTI, R. "Dez impasses para uma efectiva crítica de mídia no Brasil”, in Sala de Prensa, num. 63, at the electronic address:: http:// www.saladeprensa.org, 2004.

ERAZO, V. Panorama de la Observación Crítica de los medios de comunicación en América Latina. Santiago do Chile, 2006.

HERRERA, S."Retrato en diez rasgos de los observatorios de medios en América Latina”. In Sala de Prensa, núm. 84, at the electronic address: http://www.saladeprensa.org, 2005.

HERRERA, S. \& CHRISTOFOLETTI, R. "Mídia e Democracia: um perfil dos observatórios de meios na América Latina". In UniRevista, Vol. 1 n³, July, 2006.

REY, G. "Comunicación y democracia". In Memorias del Taller Nacional de Comunicación, convoked by Planeta Paz. Comité Intersectorial de Comunicaciones (CIC). Unimedios, Bogotá, 2002.

REY, G. "Ver desde la Ciudadanía. Observatorios y Veedurías de Medios de Comunicación en América Latina". At the electronic address: http:// www.c3fes.net/docs/verdesdelaciudadania.pdf , 2003.

TV Brasileira: 50 anos. "Mudar para não mudar". Folha de São. Paulo, September 16, 2000.

WOLTON, D. Sobre la comunicación. Madrid: Acento editorial, 1999.

Rogério Christofoletti, Journalist, PhD in Science of Communication from the University of São Paulo (USP). Professor of Journalism and of Master in Education at the Universidade do Vale do Itajaí (Univali), in the State of Santa Catarina. His research covers the field of Journalistic Ethics and relations between Education and Communication.

Susana Herrera Damas, Journalist, PhD in Communication from the University of Navarra (Spain). She works at the University of Piura (Peru), developing research regarding the analysis of radio broadcasting genres and relations between media and society. 